\title{
Early results of fixed-bearing unicompartmental knee replacement designed for the lateral compartment
}

Saeed Asadollahi ${ }^{1} \mathbb{0}$, Hannah A. Wilson², Fraser R. Thomson ${ }^{1}$, Kenneth Vaz ${ }^{1}$, Rob Middleton², Cathy Jenkins ${ }^{1}$, Abtin Alvand ${ }^{1,2}$, Nicholas Bottomley ${ }^{1}$, Chris A. Dodd ${ }^{1}$, Andrew J. Price ${ }^{1,2}$, David W. Murray ${ }^{1,2}$ and William F. Jackson ${ }^{1 *}$

\begin{abstract}
Background: Isolated lateral compartment knee arthritis is less prevalent than medial. While the reported results of medial unicompartmental knee replacement (UKR) have been good and comparable to total knee replacement, the results of lateral UKR have been mixed. We present the short-term results and survivorship of a fixed-bearing UKR designed specifically for the lateral compartment.

Methods: We report the result of 130 primary fixed-bearing lateral Oxford (FLO) UKRs (123 patients) performed between 2015 and 2019 with a minimum follow-up of 1 year. The indications for lateral UKR were: isolated lateral osteoarthritis $(n=122)$, post-trauma $(n=5)$ and osteonecrosis $(n=3)$. The mean age was $69.1( \pm 11.6)$, mean BMI 28.4 $( \pm 4.9), 66.9 \%$ female, $60 \%$ right-sided, and mean follow-up 3 (range 1-4.8 years, standard deviation \pm 1 ) years. The primary outcome measure was the Oxford knee score (OKS). Survival analysis was performed with "revision for any reason", "reoperation", and "implant failure" as the endpoints.

Results: Six patients died from unrelated reasons. None of the implants failed. One required the addition of a medial UKR for medial arthritis. There were no other reoperations. At 4 years, the survival for implant failure was $100 \%$ and for both revision and all reoperations was 99.5\% (95\% Cl 96.7-99.9\%). At the last review, at a mean of 3 years, the mean Oxford knee score was 41.

Conclusion: The good survivorship and outcome scores suggest that UKR designed for the lateral compartment is an excellent alternative to total knee replacement in selected patients with isolated lateral tibiofemoral arthritis at short-term follow-up.
\end{abstract}

Keywords: Arthroplasty, Replacement, Knee, Knee prosthesis

\section{Introduction}

Isolated lateral compartment osteoarthritis affects approximately $10 \%$ of patients with knee osteoarthritis [1]. If these patients present with symptoms and damage

*Correspondence: jacksonwfm@hotmail.com

${ }^{1}$ Nuffield Orthopaedic Centre, Oxford University Hospitals NHS Foundation Trust, Windmill Road, Headington, Oxford OX3 7LD, UK

Full list of author information is available at the end of the article suitable for joint replacement, they can be managed with a total knee arthroplasty or a lateral UKR [2-4].

A UKR has potential advantages over total knee replacement. It is less invasive, preserves bone stock, and leaves the unaffected contralateral tibiofemoral compartment intact [5]. The procedure is associated with a faster recovery, a better ROM, less complication, shorter length of stay, higher likelihood of forgetting the artificial joint, and better cost-effectiveness [3, 4, 6-11]. Many surgeons, original author(s) and the source, provide a link to the Creative Commons licence, and indicate if changes were made. The images or other third party material in this article are included in the article's Creative Commons licence, unless indicated otherwise in a credit line to the material. If material is not included in the article's Creative Commons licence and your intended use is not permitted by statutory regulation or exceeds the permitted use, you will need to obtain permission directly from the copyright holder. To view a copy of this licence, visit http://creativecommons.org/licenses/by/4.0/. The Creative Commons Public Domain Dedication waiver (http://creativeco mmons.org/publicdomain/zero/1.0/) applies to the data made available in this article, unless otherwise stated in a credit line to the data. 
however, choose to use total knee replacements as they fear high revision rates of UKR seen in Joint registries around the globe [12-15]. They are also anxious because of mixed outcomes that have been previously reported [16-20].

There are two philosophies in use with UKR, mobile and fixed bearings. Mobile bearings have the advantage of a lower rate of polyethylene wear and improved kinematics [21]. The main drawback with this design is bearing dislocation [22-25]. This is more problematic in the lateral compartment, which distracts by about $7 \mathrm{~mm}$ in flexion compared to $2 \mathrm{~mm}$ on the medial side [26]. The Oxford domed lateral UKR was developed featuring an entirely congruous articulation using a biconcave spherical bearing which increased entrapment and therefore reduced the overall dislocation rate but did not eliminate it [27].

The FLO partial knee replacement (Zimmer Biomet UK, Bridgend) was designed to achieve optimal coverage of the lateral tibia plateau based on more than 400 knee CT scans [28]. The flat articulation allows soft tissues to guide the femoral component during flexion and extension [28]. As with other fixed-bearing designs, the kinematics, especially as the knee goes into higher degrees of flexion are not as optimal as with the domed design. The FLO and domed lateral were designed to be interchangeable, allowing the surgeon to choose intra-operatively whether to implant mobile or fixed-bearing device after assessing bearing stability at the final trial.

To date, there are only few published reports on the clinical outcome and survivorship of fixed-bearing lateral UKR with large variability in clinical results and longevity $[17,18,29-35]$. The primary objective of this study was to assess the clinical effectiveness of the FLO partial knee replacement in a large cohort of patients. Our secondary objectives were to investigate complications and survivorship of this new implant in the short term.

\section{Materials and methods}

This study has been performed in accordance with the ethical standards laid down in the 1964 Declaration of Helsinki and its later amendments. This is a retrospective review of prospectively collected data on patients who underwent FLO lateral unicompartmental knee replacement. We identified 141 knees in 134 patients who underwent primary FLO lateral unicompartmental knee replacement between 2015 and 2019 and were followed for a minimum of 1 year. Bi-compartmental UKRs were excluded. Two patients were lost to follow-up. Three patients who had ACL deficiency at the time of surgery were also excluded. Six patients died for unrelated reasons at a mean of 2.1 years post-surgery. The remaining
123 patients (130 UKRs) were included and are the focus of this study.

All procedures were performed by the orthopaedic consultants who routinely perform UKR in our centre. The indications for lateral UKRs were: bone-on-bone disease in the lateral compartment or spontaneous osteonecrosis of the knee in the lateral compartment, fullthickness cartilage in the medial compartment, intact collateral and anterior cruciate ligaments and a correctable intra-articular deformity. Inflammatory arthritis and fixed valgus deformity were considered to be a contraindication. Patient factors such as age, weight, activity level, and patellofemoral joint damage proposed by Kozinn and Scott in 1989 to be contraindications for UKR have not been considered to be contraindications for the fixedbearing UKR [36, 37]. Severe wear of the lateral facet of the patellofemoral joint with bone loss and grooving is also a contraindication for UKR [38].

All procedures were performed under a tourniquet through a small lateral para-patellar approach without dislocation of the patella. A trans-patellar tendon vertical tibial cut was performed to facilitate orientation of the saw cut and internal rotation of the tibial component. The femoral component was anatomically positioned to avoid an elevation of the joint line. The bearing thickness was assessed with the knee in full extension. All tibial components were secured with polymethylmethacrylate cement. Full weight-bearing was allowed postoperatively.

The electronic patient records were reviewed for demographics, details of the operation report, BMI, and any complications during follow-up assessment visits.

Survivorship analysis was performed with the endpoint "failure of implant", "revision for any reason" and "reoperation". "Revision for any reason" was defined as operation in which at least one component was removed or changed, or a new component was added. The outcome was assessed with the latest OKS [39].The OKS was categorised into excellent (>41), good (34-41), fair (27-33), poor $(<27)[40]$.

\section{Statistical analysis}

Statistical analysis was performed using the SPSS version 20.0 software program (SPSS, Chicago, IL). Simple descriptive and frequency analysis was performed on multiple variables. Shapiro-Wilk and KolmogorovSmirnov tests were used to test for normal distribution. Unpaired $\mathrm{T}$ test was used to compare the means of normally distributed variables. The Mann-Whitney U test was used to compare the means for numeric data when the data distribution was not normal. JMP 15.1.0 statistical software (SAS, Cry, NC, USA) was used for KaplanMeier survival analysis and 95\% confidence interval (CI) 
calculations. A p-level of less than 0.05 was considered statistically significant.

\section{Results}

The mean follow-up was 3.0 years (range 1-4.8 years, $\mathrm{SD} \pm 1)$. The right side was operated on in $60 \%$ of cases. The mean age was $69.1( \pm 11.6)$ and the mean BMI $28.4 \mathrm{~kg} / \mathrm{m}^{2}\left( \pm 4.9 \mathrm{~kg} / \mathrm{m}^{2}\right)$ (Table 1). There were no intraoperative complications, implant or wound infections or thromboembolic events in our cohort. None of the patients required a blood transfusion.

There was one recorded postoperative acute kidney injury. This was appropriately medically managed without further complications. One knee required an intra-articular injection of steroid and local anaesthetic 18 months postoperatively due to ongoing lateral sided knee pain, after which the symptoms settled.

Outcome scores were obtained for 121 knees (93\%). The mean preoperative OKS was 21.3 (SD 8.44, $n=76$ ). The OKS improved significantly $(p<0.001)$ following the operation. At a mean of 3 years postoperatively, the mean OKS was 41 (SD 7.6, $n=121$ ). Sixty per cent achieved an excellent outcome, $29 \%$ a good outcome, $5 \%$ a fair outcome, and $6 \%$ a poor outcome. The causes for the fair and poor results were persistent or lingering pain in the knee, pain in the contralateral leg, or concurrent medical condition (polyneuropathy, acute myeloid leukaemia) interfering with their activities of daily living.

The preoperative OKS was not available for 54 knees. However, this group mainly had similar demographics to the preoperative group, including age (69 vs 70 years old, $P=0.6$ ), BMI (29 versus $27 \mathrm{~kg} / \mathrm{m}^{2}, p=0.62$ ), and the operative side $(p=0.43)$. There were more female patients in the group with unavailable preoperative OKS $(p=0.051)$.

Table 1 Patients' characteristics

\begin{tabular}{ll}
\hline Demographics & \\
\hline Patients (knees) & $123(130)$ \\
Male: female & $43: 87$ \\
Mean age (years) (range) & $69.1(37-91)$ \\
Male & $68.6(38-85)$ \\
Female & $69.1(37-91)$ \\
Mean body mass index $\left(\mathrm{kg} / \mathrm{m}^{2}\right)$ (range) & $28.4(20.8-40.6)$ \\
Male & $28(21.2-33.6)$ \\
Female & $28.6(20.8-40.6)$ \\
Indication for lateral UKR & \\
$\quad$ Bone on bone lateral compartment OA & $n=122$ \\
Post-trauma arthritis & $n=5$ \\
$\quad$ Osteonecrosis of the lateral femoral condyle & $n=3$ \\
\hline
\end{tabular}

A sensitivity analysis for selection bias and unmeasured confounding in missing data was performed, including a subgroup analysis of only those with recorded preoperative OKS. The result of the subgroup analysis demonstrated a statistically significant increase in the OKS (21.5 versus $39.5, p<0.001$ ).

There was one reoperation in this series, which was the addition of a medial UKR at 1 year for progression of medial compartment arthritis in a 70-year-old male. This patient was keen to have a Lateral UKR for severe lateral OA, even though he had some early medial OA. Initially, he did well following the FLO; however, he developed medial symptoms associated with the progression of medial OA. This was treated with a Medial UKR, and he had a good result from the Bi-UKR. His final OKS score was 45 (Fig. 1).

Kaplan-Meier survival analysis at 4 years with the endpoints "revision for any reason" and "any reoperation" was $99.5 \%$ (95\% confidence interval (CI) 96.7\%-99.9\%) (Figs. 2, 3). There were no implant failures, so the 4-year survival for implant failure was $100 \%$.

\section{Discussion}

This short-term study has demonstrated that patients tended to achieve a satisfactory functional outcome with a low complication rate when treated with a FLO UKR, suggesting that it is a viable option for patients with isolated lateral tibiofemoral osteoarthritis.

We demonstrated implant survivorship of $99.5 \%$ at 4 years in 130 knees with endpoint "revision for any reason". Several other series have reported the survivorship of fixed-bearing lateral UKR, with some demonstrating similarly good results: Recently, Walker et al. reported a FLO partial knee replacement survival rate of $100 \%$ at 2 years in a series of 51 patients [29]. Smith et al. showed survivorship of $95.5 \%$ at 5 years in a series of 101 AMC Uniglide implants (Corin PLC, Cirencester, UK) [33]. Edmiston et al. reported survivorship of $94 \%$ at a mean of 82 months in a series of 49 Zimmer unicompartmental knee (Zimmer, Warsaw, IN) or Zimmer Miller-Galante implants. Similar to the current study, there was no nonrevision reoperation reported in these series.

Furthermore, the survivorship result of the current study compares favourably to registry data. The data analysis from the National Joint Registry for England and Wales (NJR) shows a 93.0\% survival rate for lateral UKRs at 5 years [41]. A recently published report of Dutch registry data shows $8.9 \%$ and $12.9 \%$ revision rates at 3 and 5 years, respectively [15]. This variation in survival rate highlights the ongoing discrepancy between outcomes of UKR from cohort series and registries [8]. The discrepancy probably relates to the surgeon's practice. Most surgeons who report good results 

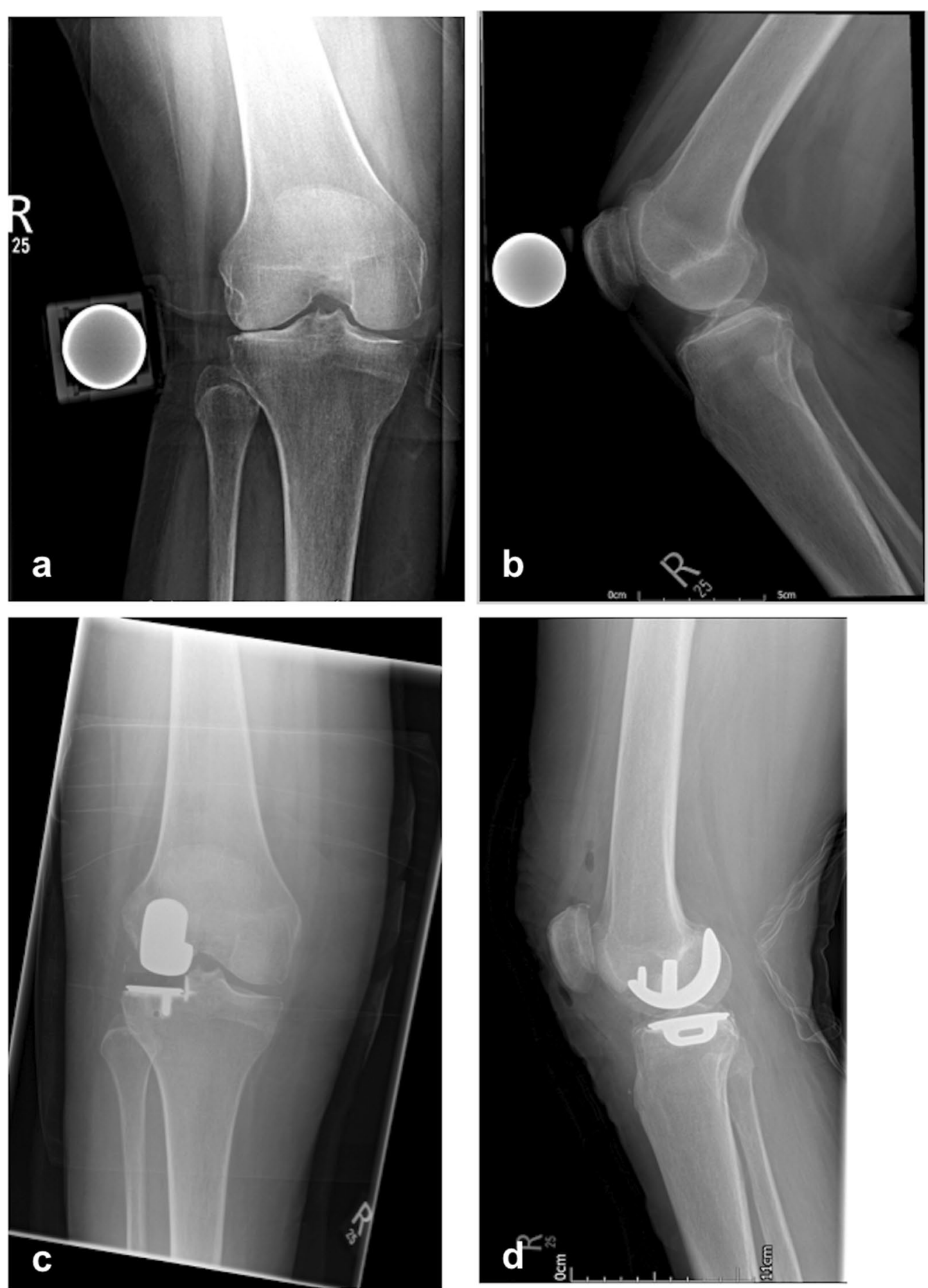

Fig. 1 a-d Pre- and postoperative X-ray of the right knee with isolated lateral OA which underwent L UKR

from cohort studies tend to be implanting reasonable numbers of UKR, whereas the commonest number of UKR done per surgeon per year recorded by the NJR is one [42]. Furthermore, often these surgeons use UKR inappropriately for patients with early arthritis [43].

The present study found that the mean 3-year postoperative OKS was 41 , which is considered to be excellent 


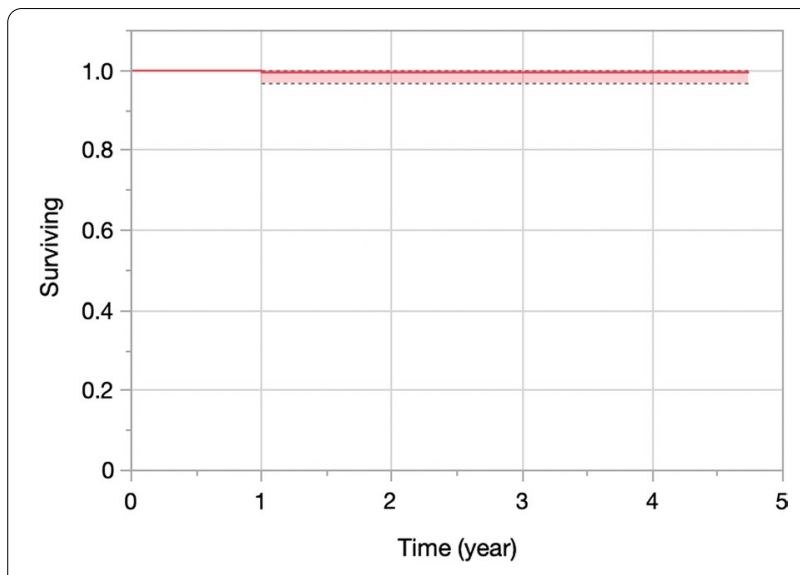

Fig. 2 Kaplan-Meier survival curve of FLO partial knee replacement with the endpoint "revision for any reason"

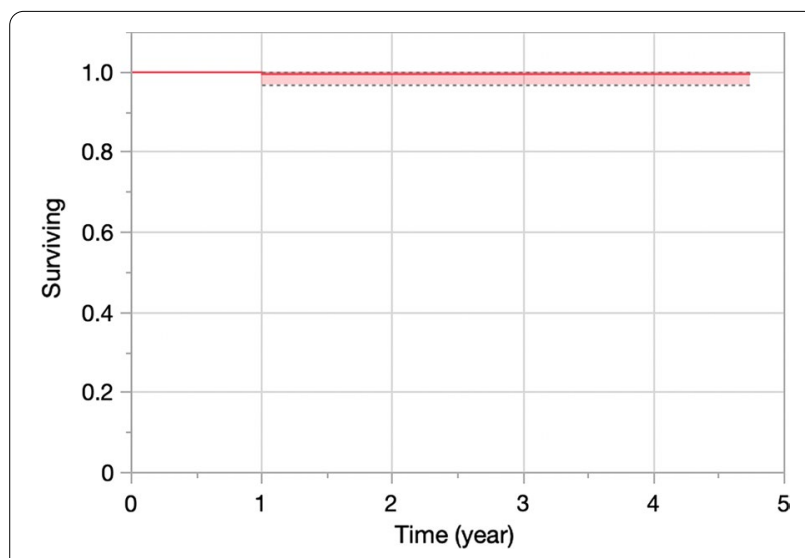

Fig. 3 Kaplan-Meier survival curve of FLO partial knee replacement with the endpoint "any reoperation"

and similar to the medial Oxford UKR (mean OKS 42 at 5 years) [44]. However, the improvement compared to preoperative score tended to be larger following lateral UKR (mean $\triangle$ OKS 20) than medial UKR (mean $\triangle$ OKS 17). This is probably a reflection of the lower preoperative score of the Lateral UKR (mean OKS 21) than the medial (mean OKS 25). This, in turn, is because many of the patients we treat with lateral UKR have more severe disease with greater deformity than would be appropriate for medial UKR. Interestingly in Walker et al. report, the mean preoperative FLO OKS was 26.4, $\triangle \mathrm{OKS}$ was 13.3 , and 2 years OKS was 39.7, perhaps suggesting they were operating on less severe lateral disease than we do [29].

Progression of disease in the adjacent compartments is the most common reason for early and late failure following lateral UKR [19, 23, 27, 45]. One of the problems lies in overcorrection after UKR [19]. A few studies with varying follow-up durations reported a revision rate of
0 to $10.2 \%$ due to contralateral OA progression 1.1 to 18.1 years after the initial surgery $[16,18,19,25,33,46]$. In the current series, there was one instance of the addition of a medial UKR at 1 year due to OA progression. This was probably a manifestation of an extended indication at the request of a high demand individual wanting to maintain a high-level activity. In order to avoid overcorrection of the deformity, we implant the femoral component anatomically and do not balance the ligaments so in flexion the normal laxity of the knee is maintained. The bearing thickness is selected in full extension, with the aim being just not to tighten the knee, so the pre-disease valgus is restored or slightly undercorrected.

This study has some limitations. The follow-up is short, making it impossible to draw any conclusion about the long-term outcome of the FLO partial knee replacement. There is a lack of a control group to compare this implant to other available fixed-bearing implants in the market. Nearly $40 \%$ of patients did not have a preoperative OKS recorded. However, there was no significant statistical difference in demographics between this group and the rest of the cohort, except for more female patients $(p=0.051)$. Furthermore, the sensitivity analysis showed that the mean postoperative OKS of those with recorded pre-operative OKS was similar to those without a recorded pre-operative OKS.

To our knowledge, this study is the largest series of the FLO partial knee replacement reported in the literature. These results show outcomes that have been observed in a high-volume centre with a specialist interest in UKR surgery. Additional work needs to be done to ensure these results are transferable to the general orthopaedic community. Further follow-up is also necessary to evaluate the mid and long-term effectiveness of the FLO partial knee replacement.

\section{Conclusions}

The early results show good functional outcome and implant survival in the knees treated with the FLO partial knee replacement. It is an attractive option for the management of isolated osteoarthritis of the lateral compartment.

\section{Abbreviations}

UKR: Unicompartmental knee replacement; ROM: Range of motion; FLO: Fixed-bearing lateral Oxford; BMI: Body mass index; OKS: Oxford knee score; OA: Osteoarthritis.

\section{Acknowledgements}

We are grateful to Barbara Marks and Jo Brown for their administrative support in the conduct of this study.

\section{Authors' contributions}

Material preparation and analysis were performed by Saeed Asadollahi, Hannah A Wilson, Fraser RThomson, Kenneth Vaz, Rob Middleton, and Cathy 
Jenkins. David W Murray, Chris A Dodd, Andrew J Price, Nicholas Bottomley, Abtin Alvand, and William F Jackson were the treating surgeons who also contributed to the study conception, design, and data collection. The first draft of the manuscript was written by Saeed Asadollahi, David W Murray, and William $F$ Jackson and all authors commented on previous versions of the manuscript. All authors read and approved the final manuscript.

\section{Funding}

Not applicable (please see the conflicts of interests).

\section{Availability of data and materials}

Data are available on request.

\section{Declarations}

\section{Ethics approval and consent to participate}

Ethical approval was sought from the local research ethics committee with formal approval deemed unnecessary under National Health Service research governance arrangements as the study was considered an audit and had institutional approval.

\section{Consent for publication}

Under National Health Service research governance arrangements, the study was considered an audit and individual consent for publication was not sought.

\section{Competing interests}

None for Saeed Asadollahi, Hannah A Wilson, Fraser RThompson, Kenneth Vaz, Rob Middleton, Cathy Jenkins. Nicholas Bottomley and Abtin Alvand received payments from Zimmer Biomet for lectures, including service on speakers bureaus. Chris Dodd and David Murray receive funding for personal and research use from Zimmer Biomet related to the subject of this article. Andrew Price received payments from Zimmer Biomet for consultancy. William Jackson received payments from Zimmer Biomet for lectures and teachings.

\section{Author details}

${ }^{1}$ Nuffield Orthopaedic Centre, Oxford University Hospitals NHS Foundation Trust, Windmill Road, Headington, Oxford OX3 7LD, UK. ${ }^{2}$ Nuffield Department of Orthopaedics, Rheumatology and Musculoskeletal Sciences, Botnar Research Centre, University of Oxford, Oxford, UK.

\section{Received: 6 October 2021 Accepted: 30 December 2021}

Published online: 05 March 2022

\section{References}

1. Scott CE, Nutton RW, Biant LC. Lateral compartment osteoarthritis of the knee: biomechanics and surgical management of end-stage disease. Bone Joint J. 2013;95-B:436-44.

2. McAuley JP, Collier MB, Hamilton WG, Tabaraee E, Engh GA. Posterior cruciate-retaining total knee arthroplasty for valgus osteoarthritis. Clin Orthop Relat Res. 2008;466:2644-9.

3. van der List JP, Chawla H, Zuiderbaan HA, Pearle AD. Patients with isolated lateral osteoarthritis: unicompartmental or total knee arthroplasty? Knee. 2016;23:968-74.

4. Walker T, Gotterbarm T, Bruckner T, Merle C, Streit MR. Total versus unicompartmental knee replacement for isolated lateral osteoarthritis: a matched-pairs study. Int Orthop. 2014;38:2259-64.

5. Pandit H, Jenkins C, Barker K, Dodd CA, Murray DW. The Oxford medial unicompartmental knee replacement using a minimally-invasive approach. J Bone Joint Surg Br. 2006:88:54-60.

6. Price AJ, Webb J, Topf H, Dodd CA, Goodfellow JW, Murray DW, et al. Rapid recovery after oxford unicompartmental arthroplasty through a short incision. J Arthroplasty. 2001;16:970-6.

7. Beard DJ, Davies $\sqcup$, Cook JA, MacLennan G, Price A, Kent S, et al. The clinical and cost-effectiveness of total versus partial knee replacement in patients with medial compartment osteoarthritis (TOPKAT): 5-year outcomes of a randomised controlled trial. Lancet. 2019;394:746-56.
8. Liddle AD, Judge A, Pandit H, Murray DW. Adverse outcomes after total and unicompartmental knee replacement in 101,330 matched patients: a study of data from the National Joint Registry for England and Wales. Lancet. 2014;384:1437-45.

9. Liddle AD, Pandit H, Judge A, Murray DW. Patient-reported outcomes after total and unicompartmental knee arthroplasty: a study of 14,076 matched patients from the National Joint Registry for England and Wales. Bone Joint J. 2015;97-B:793-801.

10. Zuiderbaan HA, van der List JP, Khamaisy S, Nawabi DH, Thein R, Ishmael C, et al. Unicompartmental knee arthroplasty versus total knee arthroplasty: Which type of artificial joint do patients forget? Knee Surg Sports Traumatol Arthrosc. 2017;25:681-6.

11. Pandit H, Hamilton TW, Jenkins C, Mellon SJ, Dodd CA, Murray DW. The clinical outcome of minimally invasive Phase 3 Oxford unicompartmental knee arthroplasty: a 15-year follow-up of 1000 UKAs. Bone Joint J. 2015:97-B:1493-500

12. Australian Orthopaedic Association National Joint Replacement Registry Annual report. 2019. https://aoanjrr.sahmri.com/annual-reports-2019. Accessed 10 May 2021.

13. New Zealand Orthopaedic Association 20 Year Report. 2019. https://nzoa. org.nz/nzoa-joint-registry. Accessed 10 May 2021.

14. National Joint Registry 16th annual report. 2019 https://reports.njrce ntre.org.uk/Portals/0/PDFdownloads/NJR16thAnnualReport2019.pdf. Accessed 10 May 2021.

15. Burger JA, Kleeblad LJ, Sierevelt IN, Horstmann WG, van Geenen RCI, van Steenbergen LN, et al. A comprehensive evaluation of lateral unicompartmental knee arthroplasty short to mid-term survivorship, and the effect of patient and implant characteristics: an analysis of data from the Dutch arthroplasty register. J Arthroplasty. 2020;35:1813-8.

16. Pennington DW, Swienckowski JJ, Lutes WB, Drake GN. Lateral unicompartmental knee arthroplasty: survivorship and technical considerations at an average follow-up of 12.4 years. J Arthroplasty. 2006;21:13-7.

17. Argenson JN, Parratte S, Bertani A, Flecher X, Aubaniac JM. Long-term results with a lateral unicondylar replacement. Clin Orthop Relat Res. 2008:466:2686-93.

18. Ashraf T, Newman JH, Evans RL, Ackroyd CE. Lateral unicompartmental knee replacement survivorship and clinical experience over 21 years. J Bone Joint Surg Br. 2002;84:1126-30.

19. Citak M, Cross MB, Gehrke T, Dersch K, Kendoff D. Modes of failure and revision of failed lateral unicompartmental knee arthroplasties. Knee. 2015;22:338-40.

20. Walker T, Zahn N, Bruckner T, Streit MR, Mohr G, Aldinger PR, et al. Midterm results of lateral unicondylar mobile bearing knee arthroplasty: a multicentre study of 363 cases. Bone Joint J. 2018;100-B:42-9.

21. Kendrick BJ, Longino D, Pandit H, Svard U, Gill HS, Dodd CA, et al. Polyethylene wear in Oxford unicompartmental knee replacement: a retrieval study of 47 bearings. J Bone Joint Surg Br. 2010;92:367-73.

22. Newman SDS, Altuntas A, Alsop H, Cobb JP. Up to 10 year follow-up of the Oxford Domed Lateral Partial Knee Replacement from an independent centre. Knee. 2017;24:1414-21.

23. Ernstbrunner L, Imam MA, Andronic O, Perz T, Wieser K, Fucentese SF. Lateral unicompartmental knee replacement: a systematic review of reasons for failure. Int Orthop. 2018;42:1827-33.

24. Gunther TVMD, Miller R, Wallace DA, Carr AJ, O'Connor JJ, McLardy-Smith P, Goodfellow JW. Lateral unicompartmental arthroplasty with the Oxford meniscal knee. Knee. 1996;3:33-9.

25. Streit MR, Walker T, Bruckner T, Merle C, Kretzer JP, Clarius M, et al. Mobilebearing lateral unicompartmental knee replacement with the Oxford domed tibial component: an independent series. J Bone Joint Surg Br. 2012:94:1356-61.

26. Tokuhara Y, Kadoya Y, Nakagawa S, Kobayashi A, Takaoka K. The flexion gap in normal knees. An MRI study. J Bone Joint Surg Br. 2004:86:1133-6.

27. Weston-Simons JS, Pandit H, Kendrick BJ, Jenkins C, Barker K, Dodd CA, et al. The mid-term outcomes of the Oxford Domed Lateral unicompartmental knee replacement. Bone Joint J. 2014;96-B:59-64.

28. Berend K, Berend M, Mauerhan D, Dodd C, Murray DW. Oxford ${ }^{\circledR}$ Fixed Lateral Partial Knee: Biomet UK Limited. 2015. https://www.oxfordpart ialknee.net/content/dam/zb-minisites/oxford-partial-knee-hcp/docum ents/us-only/0029.3-US-en-Oxford-Fixed-Lateral-SurgTech.pdf.

29. Walker T, Hariri M, Eckert J, Panzram B, Reiner T, Merle C, et al. Minimally invasive lateral unicompartmental knee replacement: Early results from 
an independent center using the Oxford fixed lateral prosthesis. Knee. 2019;27:235-41.

30. Demange MK, Von Keudell A, Probst C, Yoshioka H, Gomoll AH. Patientspecific implants for lateral unicompartmental knee arthroplasty. Int Orthop. 2015;39:1519-26.

31. Heyse TJ, Khefacha A, Peersman G, Cartier P. Survivorship of UKA in the middle-aged. Knee. 2012;19:585-91.

32. Lustig S, Lording T, Frank F, Debette C, Servien E, Neyret P. Progression of medial osteoarthritis and long term results of lateral unicompartmental arthroplasty: 10 to 18 year follow-up of 54 consecutive implants. Knee. 2014;21:S26-32.

33. Smith JR, Robinson JR, Porteous AJ, Murray JR, Hassaballa MA, Artz N, et al. Fixed bearing lateral unicompartmental knee arthroplasty-short to midterm survivorship and knee scores for 101 prostheses. Knee. 2014;21:843-7.

34. Walton MJ, Weale AE, Newman JH. The progression of arthritis following lateral unicompartmental knee replacement. Knee. 2006;13:374-7.

35. Kim KT, Lee S, Kim J, Kim JW, Kang MS. Clinical results of lateral unicompartmental knee arthroplasty: minimum 2-year follow-up. Clin Orthop Surg. 2016;8:386-92.

36. Kozinn SC, Scott R. Unicondylar knee arthroplasty. J Bone Joint Surg Am. 1989;71:145-50.

37. Pandit H, Jenkins C, Gill HS, Smith G, Price AJ, Dodd CA, et al. Unnecessary contraindications for mobile-bearing unicompartmental knee replacement. J Bone Joint Surg Br. 2011;93:622-8.

38. Beard DJ, Pandit H, Gill HS, Hollinghurst D, Dodd CA, Murray DW. The influence of the presence and severity of pre-existing patellofemoral degenerative changes on the outcome of the Oxford medial unicompartmental knee replacement. J Bone Joint Surg Br. 2007;89:1597-601.

39. Dawson J, Fitzpatrick R, Murray D, Carr A. Questionnaire on the perceptions of patients about total knee replacement. J Bone Joint Surg Br. 1998;80:63-9.

40. Moonot P, Medalla GA, Matthews D, Kalairajah Y, Field RE. Correlation between the Oxford Knee and American Knee Society scores at mid-term follow-up. J Knee Surg. 2009;22:226-30.

41. Baker PN, Jameson SS, Deehan DJ, Gregg PJ, Porter M, Tucker K. Mid-term equivalent survival of medial and lateral unicondylar knee replacement: an analysis of data from a National Joint Registry. J Bone Joint Surg Br. 2012;94:1641-8.

42. Liddle AD, Pandit $H$, Judge A, Murray DW. Optimal usage of unicompartmental knee arthroplasty: a study of 41,986 cases from the National Joint Registry for England and Wales. Bone Joint J. 2015;97-B:1506-11.

43. Kennedy JA, Mellon SJ, Lombardi AV, Berend KR, Hamilton TW, Murray DW. Candidacy for medial unicompartmental knee replacement declines with age. Orthop Traumatol Surg Res. 2020;106:443-7.

44. Mohammad HR, Kennedy JA, Mellon SJ, Judge A, Dodd CA, Murray DW. Ten-year clinical and radiographic results of 1000 cementless Oxford unicompartmental knee replacements. Knee Surg Sports Traumatol Arthrosc. 2020;28:1479-87.

45. Pandit H, Jenkins C, Beard DJ, Price AJ, Gill HS, Dodd CA, et al. Mobile bearing dislocation in lateral unicompartmental knee replacement. Knee. 2010;17:392-7.

46. Fornell S, Prada E, Barrena P, Garcia-Mendoza A, Borrego E, Domeca G. Mid-term outcomes of mobile-bearing lateral unicompartmental knee arthroplasty. Knee. 2018;25:1206-13.

\section{Publisher's Note}

Springer Nature remains neutral with regard to jurisdictional claims in published maps and institutional affiliations. 